\title{
Three-dimensional echocardiography of a subtotal mitral valve ring dehiscence
}

\section{Philippe Timmermans, Patrick Vertongen \& Filip Rega}

To cite this article: Philippe Timmermans, Patrick Vertongen \& Filip Rega (2014) Threedimensional echocardiography of a subtotal mitral valve ring dehiscence, Acta Cardiologica, 69:2, 216-217, DOI: 10.1080/AC.69.2.3017309

To link to this article: https://doi.org/10.1080/AC.69.2.3017309

\section{Published online: 23 May 2017.}

Submit your article to this journal $₫$

Џ Article views: 2

Q View related articles $₫$

View Crossmark data \lceil

4 Citing articles: 1 View citing articles 주제 


\title{
Three-dimensional echocardiography of a subtotal mitral valve ring dehiscence
}

\author{
Philippe TIMMERMANS ${ }^{1}$, MD; Patrick VERTONGEN ${ }^{2}$, MD; Filip REGA ${ }^{3}$, MD, PhD \\ ${ }^{1}$ Dept. of Cardiology, University Hospitals Leuven, Belgium; ${ }^{2}$ Dept. of Cardiology, O.-L.-Vrouw Van Lourdes Hospital, Waregem, Belgium; \\ ${ }^{3}$ Dept. of Cardiosurgery, University Hospitals Leuven, Belgium.
}

This 77-year-old patient underwent a mitral valve repair during which a mitral valve ring size 28 was inserted. Postoperative echocardiography confirmed a competent valve with only a trace of mitral valve insufficiency. Five months later, the patient presented with subacute dyspnoea and lung oedema. After initial medical stabilization, a transthoracic echocardiogram was performed. This showed a new onset massive mitral valve insufficiency. The patient was referred to our hospital for further diagnostic and therapeutic workup. With transoesophagal echocardiography in a midoesophagal view at $120^{\circ}$, the mitral valve ring was visible just above the native posterior mitral valve leaflet (red arrow). Colour Doppler flow confirmed the massive mitral valve insufficiency with a large regurgitating jet through the ring (red arrow) extending to the roof of the left atrium (blue arrow). High resolution three-dimensional reconstruction clearly showed the circumferential mitral valve ring dehiscence (yellow arrow) with residual attachment only at the posterior rim of the mitral valve apparatus (P3-A3, red arrow), and stitch material on the ring itself. Semi-urgent surgical repair was successfully performed by resecting the anterior leaflet with preservation of the posterior leaflet, and implantation of a biological 31-mm mitral valve. The postoperative observation was uneventful, and the patient was discharged from the hospital on the $15^{\text {th }}$ days after admission. He is currently doing well and is in ambulatory follow-up. 
Fig.

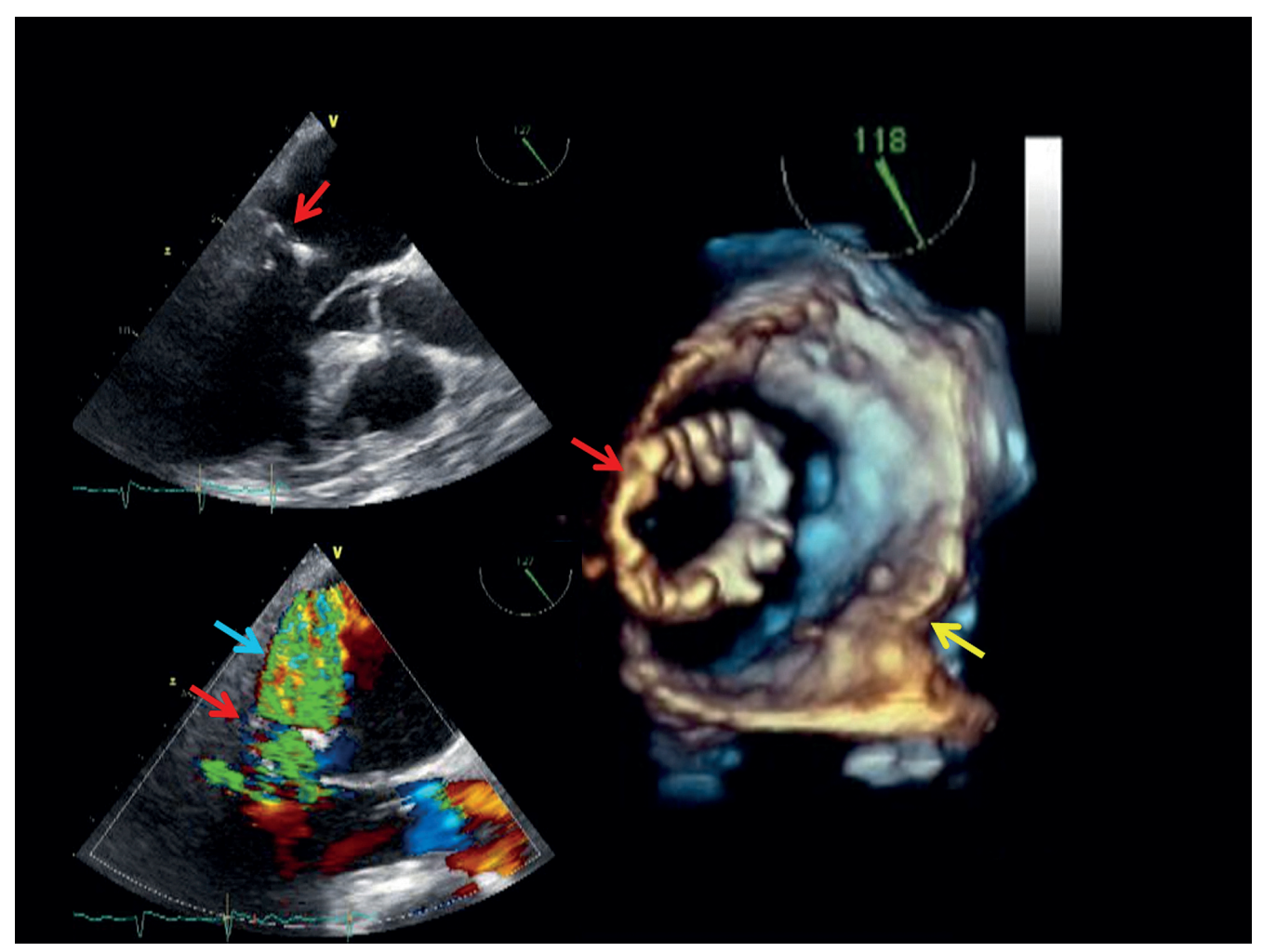

